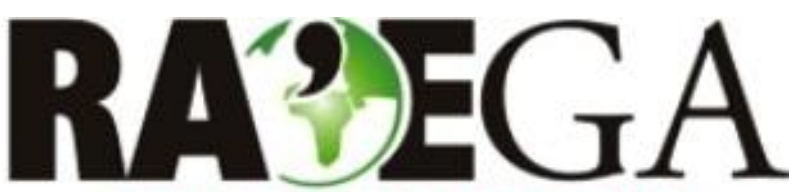

O ESPAÇO GEOGRÁFICO EM ANÁLISE

\title{
INFLUÊNCIA DOS DADOS E MÉTODOS NO MAPEAMENTO DO USO E DA COBERTURA DA TERRA
}

\section{DATA AND METHODS INFLUENCES ON LAND-USE AND LAND COVER MAPPING}

\author{
Rherison Tyrone Silva Almeida ${ }^{1}$, Alisson Neves Harmyans Moreira ${ }^{2}$, Nori Paulo Griebeler ${ }^{3}$, Sílvio Braz de \\ Sousa ${ }^{4}$
}

\section{RESUMO}

Com o intuito de analisar a influência de diferentes dados e métodos de classificação em mapeamentos de uso e cobertura da terra, submeteu-se aos seguintes objetivos: 1) quantificar as mudanças de uso e cobertura da terra durante o período de 2011 a 2014; 2) mapear e comparar o uso e cobertura da terra no ano de 2014 entre dados de diferentes plataformas orbitais. A área de estudo definida foi a bacia hidrográfica do ribeirão João Leite $\left(762 \mathrm{~km}^{2}\right)$, compreendida entre Ouro Verde e Goiânia, no estado de Goiás. O banco de dados utilizada foi composta pelas imagens orbitais dos sensores dos satélites Landsat-8 do ano de 2014 (30 metros de resolução espacial) e Theos do ano de 2011 (2 metros de resolução espacial) e um arquivo vetorial de uso e cobertura da terra de 2011 (Theos/2011). A partir de procedimentos de classificação de imagens, interpretação visual e edição vetorial foram originados os mapeamentos Landsat/2014 e Theos/Atualizado-2014. Durante o período de 2011 a 2014 houve a alteração em $18,2 \mathrm{~km}^{2}$ na bacia, relacionadas principalmente à expansão da agricultura e florestamento sobre pastagem e, a expansão de pastagem sobre vegetação densa. Em relação ao mapeamento Theos/Atualizado-2014, o Landsat/2014 superestimou a classe de vegetação densa em $58,7 \mathrm{~km}^{2}$ e subestimou as classes de pastagem, agricultura e florestamento em $50,4 \mathrm{~km}^{2}, 6,4 \mathrm{~km}^{2}$ e $3,8 \mathrm{~km}^{2}$, respectivamente. Além da escolha dos dados, a inadequada utilização de métodos e procedimentos de classificação de imagem influenciam os resultados, podendo gerar mapeamentos com informações equivocadas.

Palavras-chave: classificação de imagem; resolução espacial; escala; ribeirão João Leite.

\section{ABSTRACT}

The purpose of this study is to analyze the influence of different data and classification methods on land-use and land cover mapping, according to the following objectives: 1) to quantify land cover and land-use change from 2011 to 2014 and 2) to map and compare land-use and land cover in between data from different orbital platforms. The chosen study area was Joao Leite Watershed $\left(762 \mathrm{~km}^{2}\right)$, which has both great socioeconomic and environmental importance to the Goiania Metropolitan Area (Goias State, Brazil). The database was composed by satellite images from the sensors of Landsat-8 OLI for 2014 (30 meter spatial resolution) and Theos for 2011 (2 meter spatial resolution), as well as a land-use and land cover vector file for 2011 (Theos/2011). The mappings of Landsat/2014 and Theos/Atualizado-2014 were originated from image classification, visual interpretation and vector editing procedures. From the period of 2011-2014 there was a change of $18.2 \mathrm{~km}^{2}$ in Joao Leite Watershed, primarily related to agricultural and forestry expansion into pastureland, and pasture expansion into dense vegetation. Regarding the Theos/Atualizado-2014 mapping, Landsat/2014 overestimated the dense vegetation class (by 58.7 $\mathrm{km}^{2}$ ) and underestimated the pasture (by $50.4 \mathrm{~km}^{2}$ ), agriculture (by $6.4 \mathrm{~km}^{2}$ ) and forestry classes (by $3.8 \mathrm{~km}^{2}$ ). Besides the variation from data choices, inappropriate use of image classification methods and procedures may also influence the results, which can generate incorrect information maps.

Key-words: image classification; spatial resolution; scale; Joao Leite river.

Recebido em: 18/08/2016

Aceito em: 17/08/2017

\footnotetext{
1 Universidade Federal de Goiás, Goiânia/GO, e-mail: rherison.almeida@gmail.com

2 Universidade Federal de Goiás, Goiânia/GO,e-mail: alissonharmyans@gmail.com

${ }^{3}$ Universidade Federal de Goiás, Goiânia/GO, e-mail: griebeler@yahoo.com.br

${ }^{4}$ Universidade Estadual de Goiás, Itapuranga/GO, e-mail: sousasb@gmail.com
} 


\section{INFLUÊNCIA DOS DADOS E MÉTODOS NO MAPEAMENTO DO USO E DA COBERTURA DA TERRA}

\section{INTRODUÇÃO}

O aumento populacional, acompanhado pelo crescente processo de desenvolvimento urbano e agroindustrial tem exercido grandes impactos sobre os recursos naturais. Segundo Xavier et al. (2010, p.52), a degradação ambiental tem se tornado mais evidente, exigindo, cada vez mais, não apenas a reversão deste processo, mas também a previsão de danos futuros com base no planejamento e na gestão dos recursos naturais.

Por esta razão, torna-se de grande importância a utilização de ferramentas para a análise ambiental, as quais, atualmente são baseadas em inovações tecnológicas que surgiram a partir da década 1970. Dentre estas ferramentas, temos o sensoriamento remoto com gerador de informações, se constituindo a principal forma atual de fazer cartografia.

Como instrumento derivado de produtos de sensoriamento remoto, temos os mapas de uso e cobertura da terra, os quais permitem acompanhar sistematicamente as mudanças na paisagem, fornecendo informações que podem nortear o diagnóstico e a tomada de decisão frente a impactos ambientais (SILVA et al., 2013, p.118).

O mapeamento do uso e da cobertura da terra pode ser realizado de forma manual por meio de interpretação visual de imagens (vetorização) ou automatizada por meio de algoritmos classificadores, supervisionados ou não supervisionados. De toda forma, esta técnica é conhecida como Classificação Digital de Imagens, que é quando se rotula um pixel da imagem, atribuindo a ele uma classe, que identifica como aquela porção do território é usada.

$\mathrm{Na}$ interpretação visual, o analista extrai informações da superfície terrestre por meio da observação das imagens, delimitando manualmente as classes de interesse. Apesar de ser uma técnica eficiente quanto à classificação, demanda tempo, principalmente quando aplicada a áreas extensas (VASCONCELOS, 2004, p.488). Por outro lado, os algoritmos para classificação surgiram como uma técnica que possibilita a identificação automática e a transformação das áreas de uso e cobertura da terra em mapas temáticos. Contudo, nem sempre os resultados são satisfatórios, exigindo análise posterior à classificação, visando a correção de erros dos analistas e/ou algoritmos classificadores.

Outro fator determinante na qualidade da classificação está relacionado aos dados que serão utilizados, sobretudo ao nível de detalhamento, o que normalmente está relacionado à escala, que, no caso de imagens para sensoriamento remoto, vincula-se à resolução espacial. Dependendo da finalidade, dados em escalas de menor detalhamento podem ser adequadas para estudos em escala de abrangência regional ou global. Porém, no caso de estudos em escala local ou que se exige maior detalhamento, a utilização de dados de melhor resolução espacial é um ponto preponderante, podendo resultar em produtos com maior confiabilidade.

Assim, o conceito de plataforma deve ser considerado na hora da definição do dado mais adequado. Sabe-se que o conceito de plataforma está atrelado ao nível de aquisição do dado (orbital, aéreo, terrestre). Todavia, o conceito é mais abrangente, já que cada plataforma orbital, possui sensores com diferentes resoluções espaciais, espectrais, radiométricas e temporais, ademais, traçam diferentes tipos de orbita em torno do planeta. Tais parâmetros intrínsecos ao sensor, resultam em dados com características muito distintas e especificidade de aplicação.

Em teses, dissertações, artigos científicos e documentos oficiais, por exemplo, pode ser comum encontrar a utilização de dados inapropriados às escalas dos estudos, podendo gerar informações equivocadas, sem a devida discussão acerca dos resultados. Ademais, visto a grande quantidade de trabalhos com a temática uso e cobertura da terra, que se valem principalmente de imagens da série Landsat, se faz importante estudos que analisem diferentes dados, com diferentes resoluções espacial, sob 


\section{INFLUÊNCIA DOS DADOS E MÉTODOS NO MAPEAMENTO DO USO E DA COBERTURA DA TERRA}

regime de diferentes métodos de classificação, afim, de traçar um perfil crítico de resultados

Nesse contexto, com o intuito de analisar a influência de diferentes dados de sensoriamento remoto e das diferentes técnicas de classificação (automatizada e interpretação visual) em mapeamentos do uso e da cobertura da terra, utilizando como área de estudo a Bacia Hidrográfica do Ribeirão João Leite (BHRJL), submeteu-se este trabalho aos seguintes objetivos: 1) quantificar as mudanças de uso e cobertura da terra durante o período de 2011 a 2014; 2) Mapear e comparar o uso e a cobertura da terra no ano de 2014 entre dados originados a partir de diferentes plataformas orbitais. Especificamente, o sensor OLI (Operational Land Imager) do satélite Landsat 8 e o sensor Theos (Thailand Earth Observation Satellite).

\section{MATERIAIS E MÉTODOS}

\section{1 ÁREA DE ESTUDO}

A BHRJL (Figura 1) possui área aproximada de $762 \mathrm{~km}^{2}$, estando localizada no estado de Goiás, abrangendo parte dos municípios de Goiânia, Nerópolis, Goianápolis, Terezópolis de Goiás, Anápolis, Campo Limpo de Goiás e Ouro Verde de Goiás.
Essa bacia possui grande importância socioeconômica e ambiental para a Região Metropolitana de Goiânia (GO). Em 2010, 35\% dos produtos hortifrúti vendidos na Central de Abastecimento do estado de Goiás foram produzidos em seus domínios (CEASA-GO, 2011, p. 45). Além disso, situa-se o local da barragem do Ribeirão João Leite, responsável pelo fornecimento de água para a cidade de Goiânia, e parcialmente para Trindade e Aparecida de Goiânia, atendendo a aproximadamente 1.896.975 habitantes. Contudo, de acordo com a Saneago (empresa responsável pelo saneamento do estado de Goiás) tem como meta garantir o abastecimento a 2.352.069 de habitantes em total plenitude até o ano de 2025.

Atualmente, a BHRJL participa do Programa Produtor de Águas, de iniciativa da Agência Nacional das Águas (ANA), um dos maiores programas do gênero no Brasil, abrigando mais de 700 produtores rurais. O programa tem como objetivo a redução da erosão e assoreamento dos mananciais nas áreas rurais, o qual propõe ações de conservação da água e do solo na bacia, além de Pagamento por Serviços Ambientais (PSA). 


\section{INFLUÊNCIA DOS DADOS E MÉTODOS NO MAPEAMENTO DO USO E DA COBERTURA DA TERRA}

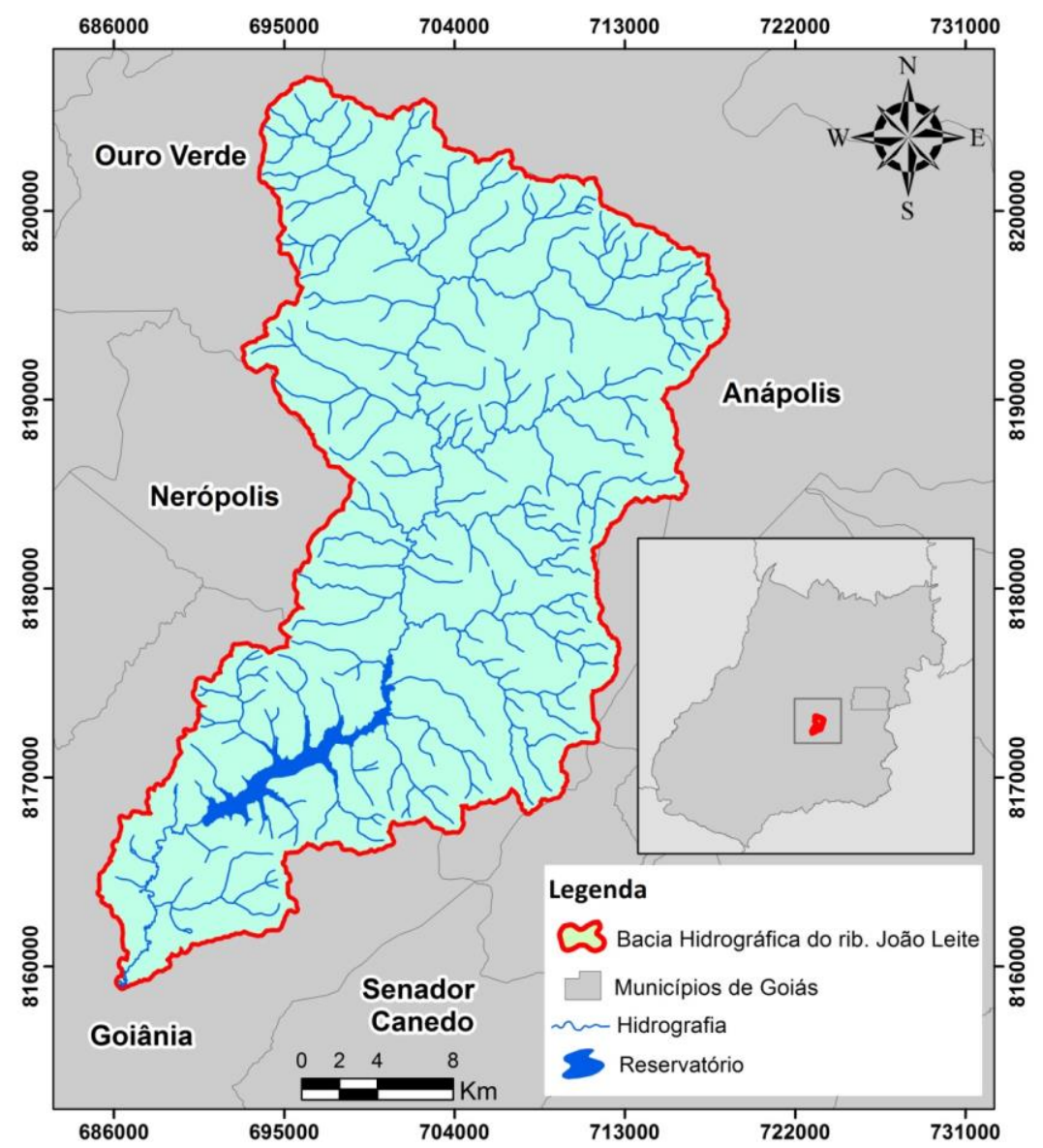

Figura 1 - Localização da bacia hidrográfica do ribeirão João Leite. Fonte: Bioma Brasil (2013).

\subsection{CLASSIFICAÇÃO DO USO E COBERTURA DO SOLO}

Foram utilizados três mapeamentos de uso e cobertura da terra da BHRJL, os quais são chamados aqui de: Theos/2011, Theos/Atualizado-2014 e Landsat/2014. Os mapeamentos Theos/2011 e Landsat/2014 foram gerados a partir da classificação das imagens orbitais dos sensores dos satélites Theos e Landsat-8, respectivamente. Enquanto que, o mapeamento Theos/Atualizado-2014 foi gerado por meio de atualização do arquivo vetorial do mapeamento Theos/2011. Essa atualização consistiu na edição vetorial por interpretação visual associando a imagem orbital Landsat-8 OLI de 2014 e imagens de alta resolução espacial do ano de 2014 disponíveis no software Google Earth. Os procedimentos para obtenção desses mapeamentos são ilustrados de forma sucinta na Figura 2.
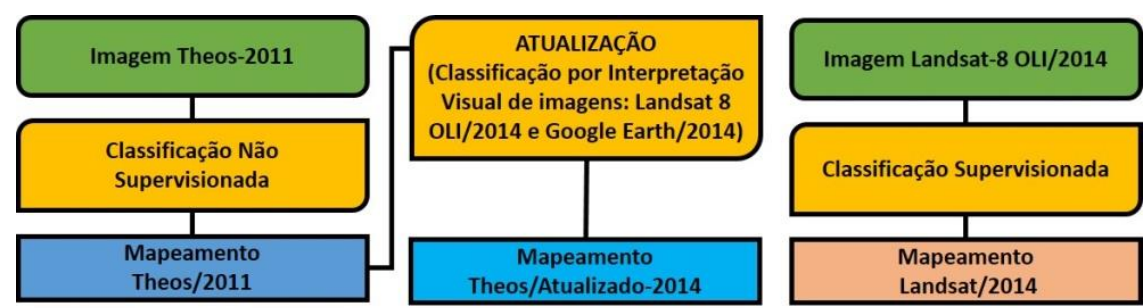

Figura 2 - Fluxograma referente ao conjunto de dados e procedimentos metodológicos empregados na geração dos três mapeamentos de uso e cobertura da terra: Theos/2011, Theos/Atualizado-2014 e Landsat/2014. Fonte: Autores. 


\section{INFLUÊNCIA DOS DADOS E MÉTODOS NO MAPEAMENTO DO USO E DA COBERTURA DA TERRA}

\subsubsection{MAPEAMENTO THEOS/2011}

O mapeamento Theos/2011 foi elaborado pela Organização da Sociedade Civil de Interesse Público (OSCIP) Bioma Brasil no âmbito do projeto Diagnóstico Socioambiental da Bacia Hidrográfica do Ribeirão João Leite (BIOMA BRASIL, 2013, p.15), financiado pela Agência Nacional das Águas (ANA). Esse mapeamento é derivado de uma classificação não supervisionada da imagem orbital do satélite Thailand Earth Observation Satellite (Theos), o qual teve passagem no dia 05 de agosto de 2011.

A imagem Theos, foi submetida aos procedimentos de fusão entre a banda pancromática ( 2 metros de resolução espacial) e as bandas multiespectrais (15 metros de resolução espacial), realce, equalização, mosaico e, ortorretificação. A fusão resultou em uma composição colorida com resolução espacial de 2 metros, com projeção UTM (Universal Transversa de Mercator) e Datum SIRGAS 2000 (fuso 22S).

Utilizando o software ENVI 4.8, na classificação da composição colorida da imagem de satélite Theos, foi adotado uma abordagem não supervisionada, por meio do algoritmo Iso Cluster, o qual consiste no agrupamento de células (clustering). Após a delimitação automática de classes foi feita inspeção visual e edição vetorial, a fim de se construir um mapeamento com as classes de uso e cobertura da terra: vegetação densa, áreas úmidas, agricultura, pastagem, florestamento, edificações, massa d'água, mineração, solo exposto e área urbana. Os critérios para a adoção desta legenda no mapeamento foram os definidos pelo edital da ANA quando foi dada a seleção da OSCIP para realização do trabalho técnico, todavia, elas retratas as práticas sociais existentes na região, que refletem na paisagem e na forma de apropriação do território.

\subsubsection{MAPEAMENTO THEOS/ATUALIZADO-2014}

O mapeamento Theos/Atualizado-2014, utilizado como referência para comparação nesse trabalho foi derivado da atualização do arquivo vetorial do mapeamento Theos/2011. Os dados utilizados para esta atualização foram os do satélite Landsat-8 OLI (Operational Land Imager) e das imagens orbitais de alta resolução espacial disponíveis no software Google Earth.

Os dados do Landsat-8 OLI, adquiridos no site do Serviço Geológico Estadunidense (http://earthexplorer.usgs.gov), foram os de órbita/ponto 222/71, o qual teve passagem no dia 08 de julho de 2014 (estação seca). As imagens orbitais do sensor imageador OLI a bordo do satélite Landsat-8 consistem de nove bandas espectrais. Sendo oito bandas multiespectrais de resolução espacial de 30 metros (bandas 1 a 7 e 9) e, uma banda pancromática de resolução espacial de 15 metros (banda 8).

Utilizando o Sistema de Informações Geográficas (SIG) QGIS (SHERMAN et al., 2014), realizou-se a composição colorida falsa cor das bandas multiespectrais 6 (Infravermelho médio 1.57 - $1.65 \mu \mathrm{m}$ ), 5 (Infravermelho próximo - 0.85 $0.88 \mu \mathrm{m})$ e 4 (Vermelho $0.64-0.67 \mu \mathrm{m}$ ). Após isso, submeteu-se a composição aos processos de reprojeção (para o Datum SIRGAS 2000 Fuso 22S) e georreferenciamento. No procedimento de georreferenciamento utilizou-se como base a imagem orbital Theos, tendo por objetivo proporcionar sinergia entre os dois dados, visando as futuras comparações entre os mapeamentos.

Sendo assim, em ambiente SIG, iniciouse os procedimentos de classificação por interpretação visual sobrepondo o arquivo vetorial do mapeamento Theos/2011 à imagem orbital Landsat-8 OLI, inspecionando visualmente, todos os polígonos alterados durante o período do 2011 a 2014. Ao observar divergências de uso e cobertura da terra entre o arquivo vetorial e a imagem orbital, procedeu-se às etapas de validação e posteriormente, às de correção vetorial, utilizando como referência para ambos procedimentos, as imagens de 2014 disponíveis no software Google Earth, através do plugin Open Layers presente no software QGIS, entre o período de agosto de 2011 a julho de 2014.

A etapa de validação permitiu confirmar as alterações de uso e cobertura da terra 


\section{INFLUÊNCIA DOS DADOS E MÉTODOS NO MAPEAMENTO DO USO E DA COBERTURA DA TERRA}

ocorridas no período, como exemplificado na Figura 3.
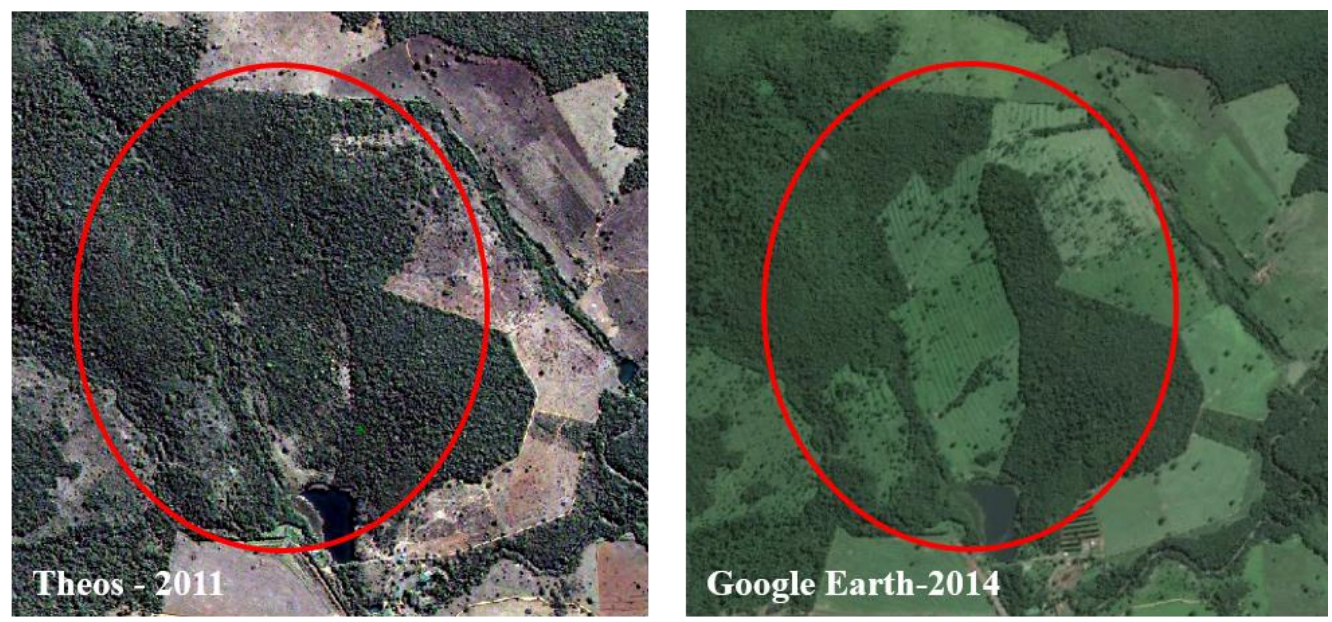

Figura 3 - Conversão de áreas de vegetação nativa (2011) para pastagens (2014). Fonte: Bioma Brasil (2013) e Google Earth (2014).

Dessa forma, na segunda etapa, tanto para o mapeamento Theos/2011 quanto para o Theos/Atualizado-2014 realizou-se as operações de correção vetorial, tais como: adição, remoção e edição de polígonos. Assim, seguindo esses procedimentos para todos os polígonos não identificados ou alterados (durante o período de 2011 a 2014), realizou-se a atualização do mapeamento Theos/2011, originando o mapeamento Theos/Atualizado-2014.

\subsubsection{MAPEAMENTO LANDSAT/2014}

O mapeamento Landsat/2014 foi originado a partir de uma classificação supervisionada utilizando os mesmos dados Landsat-8 OLI empregados na elaboração do mapeamento Theos/Atualizado-2014. O SIG utilizado para a classificação dessa imagem foi o Spring versão 5.2.7 (CÂMARA et at., 1996, p.13), no qual, foi realizada a segmentação da imagem. O método de segmentação definido foi o de crescimento por regiões e, os valores adotados para os limiares de similaridade e área, foram 30 e 35 , respectivamente.

A partir da segmentação, no processo denominado treinamento, foram coletadas amostras de segmentos referentes às classes de pastagem, vegetação densa, agricultura, área urbana, florestamento, massa d'água e solo exposto. A quantidade de classes foi inferior à do mapeamento Theos/2011 e Theos/Atualizado2014 devido principalmente à diferença de resolução espacial, que limitou o algoritmo classificador à distinção mais detalhada de feições. Dessa forma, para compatibilizar as legendas, exclusivamente nas tabelas comparativas, as classes de vegetação densa e área úmida existentes nos mapeamentos Theos/2011 e Theos/Atualizado-2014 foram unificadas, possibilitando assim, confrontar igualitariamente com a classe de vegetação densa do mapeamento Landsat/2014. As classes de edificações, mineração e solo exposto, não foram consideradas nas comparações de quantificação devido à baixa representatividade na bacia, inferior a $1,2 \mathrm{~km}^{2}$.

$\mathrm{Na}$ etapa de classificação foi escolhido o classificador Bhattacharya (algoritmo de classificação supervisionada por regiões), com limiar de aceitação de $99 \%$.

Por fim, o arquivo vetorial do mapeamento de uso e cobertura da terra Landsat/2014 foi submetido à edição e inspeção visual em escala adequada ao dado, 1:80.000. Nessa última etapa foram corrigidos os erros de classificação (ou interpretação) entre classes, comumente cometidos pelos algoritmos de classificação. 


\section{INFLUÊNCIA DOS DADOS E MÉTODOS NO MAPEAMENTO DO USO E DA COBERTURA DA TERRA}

\section{RESULTADOS E DISCUSSÃO}

\subsection{USO E COBERTURA DA TERRA THEOS/ATUALIZADO-2014}

A Figura 4 apresenta o mapeamento de uso e cobertura da terra Theos/Atualizado-2014. A classe predominante na BHRJL é a de pastagens, correspondendo a 58,9\% (449 $\left.\mathrm{km}^{2}\right)$. Em menor quantidade, as áreas de vegetação densa constituem-se segunda classe predominante, abrangendo 22,2\% (169 $\left.\mathrm{km}^{2}\right)$. Esse tipo de uso é majoritário nas regiões norte, centro-oeste e principalmente na região sul da bacia, local onde se situa o reservatório de abastecimento público e, inclusive, o Parque Estadual Altamiro de Moura Pacheco (PEAMP), unidade de conservação de proteção integral criada pela Lei estadual no 11.878 em 30 de dezembro de 1992.

As áreas agrícolas ocupam 7,4\% (56,2 $\mathrm{km}^{2}$ ). Conforme constatado por Sousa (2013, p.166), a produção de hortifruti é a atividade agrícola predominante na BHRJL. O referido autor cita que os principais produtos cultivados são: inhame, cará, batata doce, chuchu, pepino, beterraba, milho verde, jiló, tangerina, abobora, pimentão, berinjela, tomate, repolho, vagem, cenoura, quiabo banana, alho, laranja, batata e cebola. Boa parte desses produtos são responsáveis pelo abastecimento alimentício da Região Metropolitana de Goiânia (RMG).

Quanto às áreas urbanas, estas ocupam 4,5\% (34,6 km²), sendo os municípios de Goiânia e Anápolis os mais urbanizados, os quais concentram $86,4 \%$ do total das áreas urbanas da bacia. Apesar dos limites geográficos dos municípios de Nerópolis e Ouro Verde abrangerem o território da bacia, as sedes urbanas não estão inseridas.

As áreas identificadas como florestamento abrangem 2,9\%, ou $21,7 \mathrm{~km}^{2}$. São representadas pelo cultivo de espécies arbóreas para produção de madeira, celulose, carvão vegetal, etc., como por exemplo, os eucaliptos.

Em relação às áreas classificadas como área úmida, estas compõem 2,6\%, ou $20,4 \mathrm{~km}^{2}$. Essas áreas são representadas por fitofisionomias como o campo limpo, caracterizada por áreas de solos mal drenados, próximos ao lençol freático. Quanto ao nível de conservação dessas áreas, não se pode comparar com as áreas classificadas como vegetação densa, pois, em épocas de estiagem, quando o nível freático baixa $\mathrm{e}$ possibilita a passagem do gado, muitas das vezes estas são utilizadas como pastagem.

Lagos, lagoas e represas foram classificados como massa d'água, e abrangem $1,9 \%$. Outras classes que também possuem menor representatividade e permitiram ser identificadas devido à boa resolução espacial da imagem orbital do sensor Theos foram: as de edificações $(0,06 \%)$, que compreendem as construções situadas fora dos perímetros urbanos; áreas de mineração $(0,04 \%)$ e, solo exposto $(0,06 \%)$. 


\section{INFLUÊNCIA DOS DADOS E MÉTODOS NO MAPEAMENTO DO USO E DA COBERTURA DA TERRA}

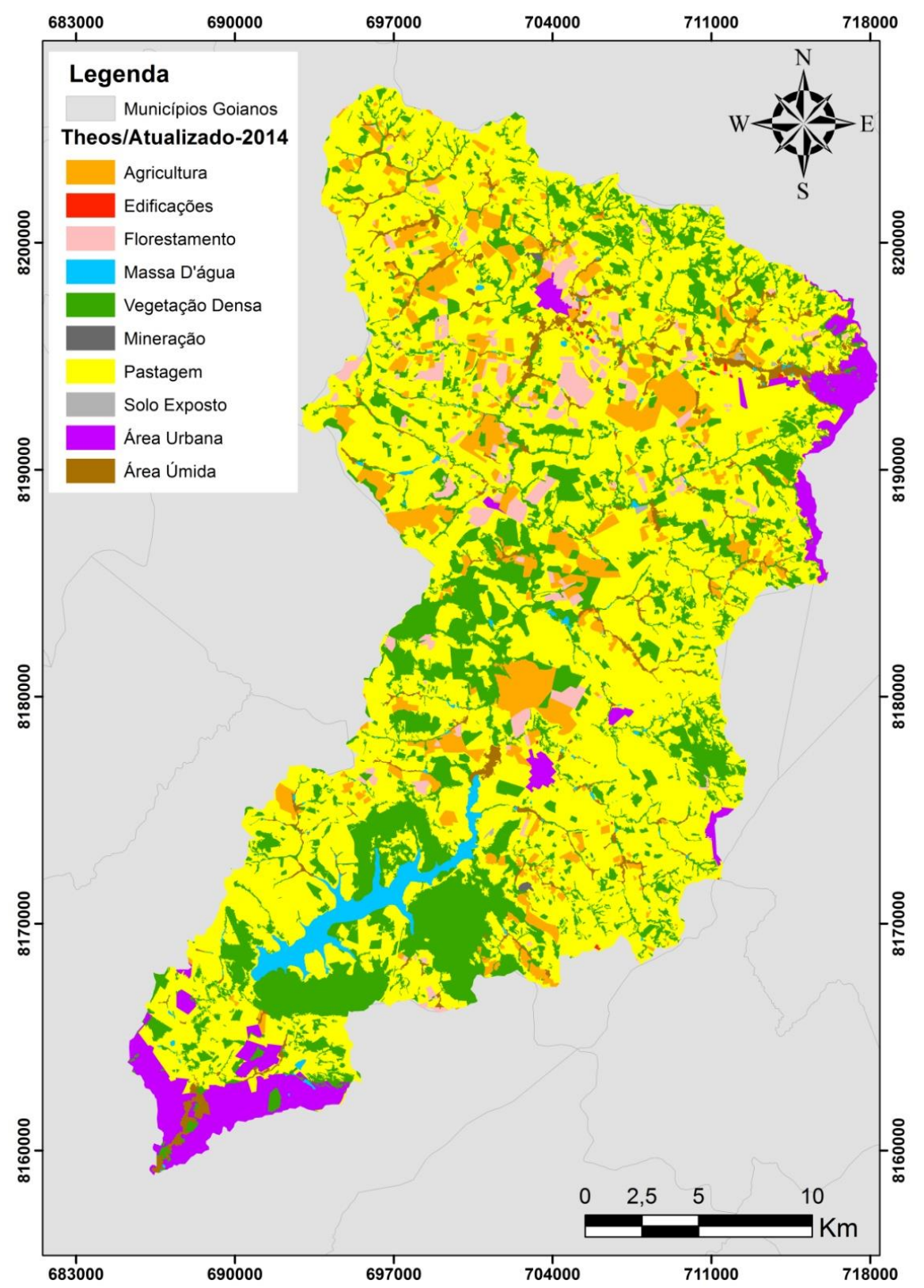

Figura 4 - Mapeamento de Uso e Cobertura da Terra Theos/Atualizado-2014. Fonte: Autores.

3.2 ANÁLISE COMPARATIVA ENTRE OS MAPEAMENTOS DE USO E COBERTURA DA TERRA THEOS/2011 E THEOS/ATUALIZADO 2014

A análise comparativa entre os mapas de uso e cobertura da terra ocorreu entre o mapeamento Theos/Atualizado-2014 (Figura 4) e o mapeamento Theos/2011 (Figura 5). Visualmente, as modificações ocorridas ao longo desses últimos três anos são pouco perceptíveis, haja vista que a área já apresenta alto nível de conversão de sua vegetação nativa em atividades antrópicas. 


\section{INFLUÊNCIA DOS DADOS E MÉTODOS NO MAPEAMENTO DO USO E DA COBERTURA DA TERRA}

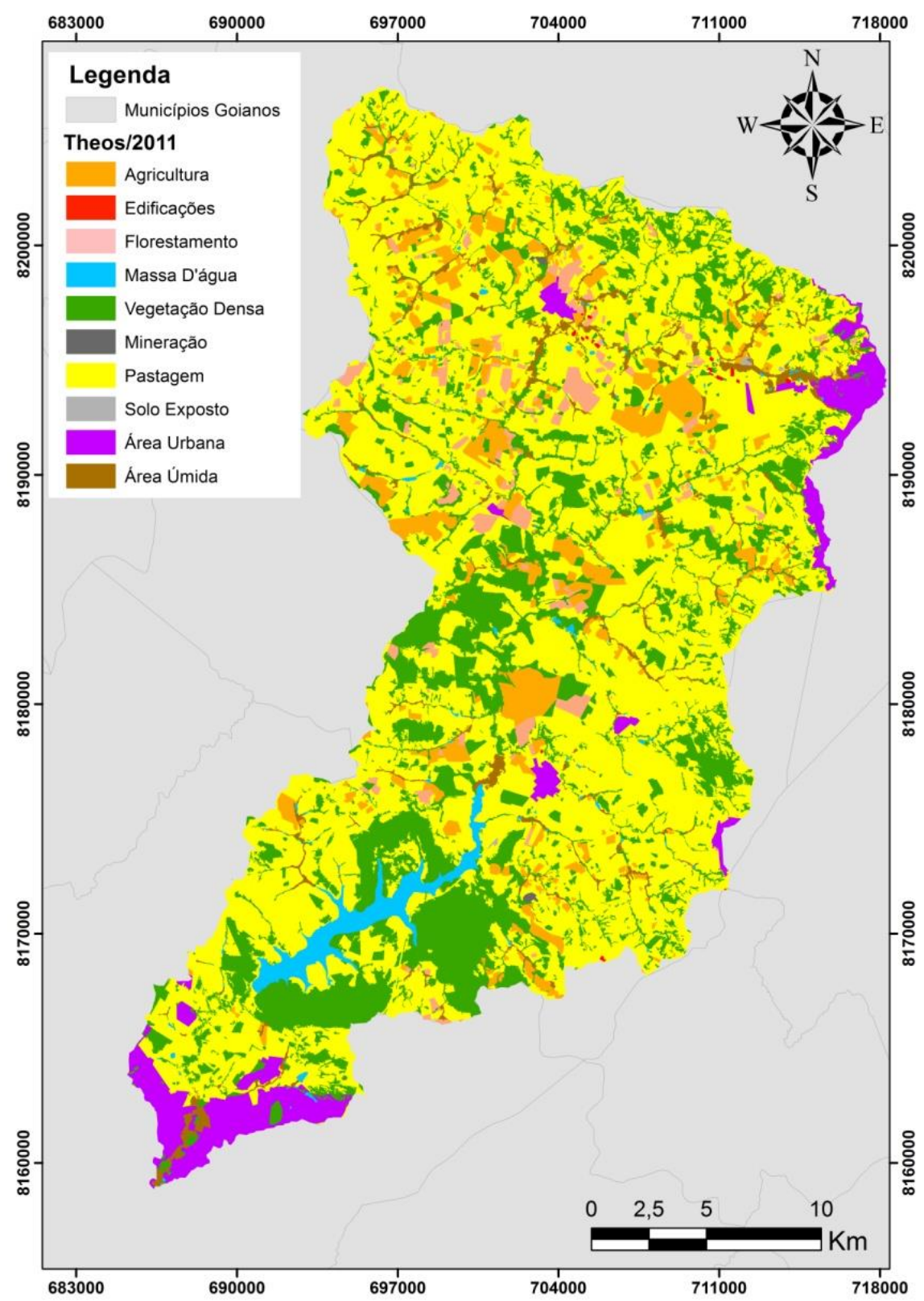

Figura 5 - Mapeamento de uso e cobertura da terra Theos/2011. Fonte: Bioma Brasil (2013).

No entanto, ao realizar a quantificação das classes desses dois mapeamentos, é possível observar detalhadamente diferenças consideráveis quanto a extensão da cobertura e as modificações do uso e cobertura da terra.
Dessa forma, na Tabela 1 é apresentada a comparação entre o mapeamento de 2011 e o de 2014 para cada classe temática, incluindo o tamanho das áreas que foram expandidas ou suprimidas. 


\section{INFLUÊNCIA DOS DADOS E MÉTODOS NO MAPEAMENTO DO USO E DA COBERTURA DA TERRA}

Tabela 1 - Quantificação das classes de uso e cobertura da terra durante o período de 2011 a 2014 na bacia hidrográfica do ribeirão João Leite. Fonte: Autores.

\begin{tabular}{cccccc}
\hline & \multicolumn{2}{c}{ Theos/2011 } & \multicolumn{2}{c}{ Theos/Atualizado-2014 } & $\begin{array}{c}\text { Expansão (+) ou } \\
\text { Slasse }\end{array}$ \\
\cline { 2 - 6 } & $\mathrm{Km}^{\mathbf{2}}$ & $\%$ & $\mathrm{Km}^{\mathbf{2}}$ & $\%$ & $\mathrm{Km}^{\mathbf{2}}$ \\
\hline Pastagem & 451,1 & 59,2 & 444,2 & 58,3 & $-6,9$ \\
Veg. Densa & 170,1 & 22,3 & 169,0 & 22,2 & $-1,1$ \\
Agricultura & 51,7 & 6,8 & 56,2 & 7,4 & $+4,5$ \\
Área Urbana & 33,8 & 4,4 & 34,6 & 4,5 & $+0,8$ \\
Florestamento & 19 & 2,5 & 21,7 & 2,8 & $+2,7$ \\
Área Úmida & 20,4 & 2,7 & 20,4 & 2,7 & 0,0 \\
Massa d'água & 14,6 & 1,9 & 14,6 & 1,9 & 0,0 \\
Edificações & 0,5 & 0,07 & 0,5 & 0,07 & 0,0 \\
Mineração & 0,3 & 0,04 & 0,3 & 0,04 & 0,0 \\
Solo Exposto & 0,4 & 0,05 & 0,4 & 0,05 & 0,0 \\
\hline Total & 762 & 100 & 762 & 100 & - \\
\hline
\end{tabular}

As classes que obtiveram a maior expansão nos últimos três anos foram as de agricultura e florestamento. Enquanto que, as classes de pastagem e vegetação densa foram as sofreram redução. A classe de agricultura responsável pela maior expansão na BHRJL, a qual correspondeu a $4,5 \mathrm{~km}^{2}$. Foi identificado que toda essa expansão ocorreu sobre as áreas que, em 2011, estavam cobertas por pastagens. Quanto à classe de florestamento, esta obteve expansão de $2,7 \mathrm{~km}^{2}$, a qual também ocorreu sobre áreas que antes eram ocupadas de pastagens.

As áreas urbanas expandiram $0,8 \mathrm{~km}^{2}$ em 2014. Essa expansão ocorreu principalmente sobre áreas de pastagens localizadas no município de Goiânia, limítrofes a área urbana já consolidada.

Quanto às classes que sofreram supressão, a classe de vegetação densa foi suprimida em $1,1 \mathrm{~km}^{2}$. Esse valor corresponde ao desmatamento ocorrido em função da conversão para pastagens.
A classe de pastagem foi a que obteve a maior redução em extensão, a qual correspondeu a $6,9 \mathrm{~km}^{2}$. Esse valor correspondeu à diferença entre a expansão de $1,1 \mathrm{~km}^{2}$ (sobre vegetação densa) e à supressão de $8 \mathrm{~km}^{2}\left(4,5 \mathrm{~km}^{2}\right.$ para agricultura, 2,7 $\mathrm{km}^{2}$ para florestamento e 0,8 para área urbana) que ocorreram durante 0 período analisado.

Em relação às classes de área úmida, edificações, mineração, solo exposto e massa d'água, as alterações observadas foram inferiores a $0,1 \mathrm{~km}^{2}$.

Após a quantificação das mudanças de cobertura e uso da terra observou-se que, durante o período de 2011 a 2014 detectou-se a mudança em $18,2 \mathrm{~km}^{2}$ na BHRJL.

\subsection{COMPARAÇÃO ENTRE O MAPEAMENTO LANDSAT/2014 E O THEOS/ATUALIZADO-2014}

A Figura 6 apresenta o mapeamento Landsat/2014. Como a imagem orbital Landsat-8 OLI possui menor resolução espacial quando comparada com a do satélite Theos, logo 


\section{INFLUÊNCIA DOS DADOS E MÉTODOS NO MAPEAMENTO DO USO E DA COBERTURA DA TERRA}

proporcionou maior limitação à distinção de feições. Como exemplo disso, observa-se na Figura 7 que no mapeamento Theos/Atualizado2014 houve a separação das classes vegetação densa e área úmida, o que não ocorreu no caso do mapeamento Landsat/2014, que a classificou como uma única classe, correspondente à de vegetação densa. Em termos de gestão ambiental da área, essa influência dos dados de pior resolução pode permitir que as áreas úmidas sejam ignoradas do processo de planejamento, ou que não sejam protegidas por força de legislação haja vista falta detalhes e informação cartográfica.

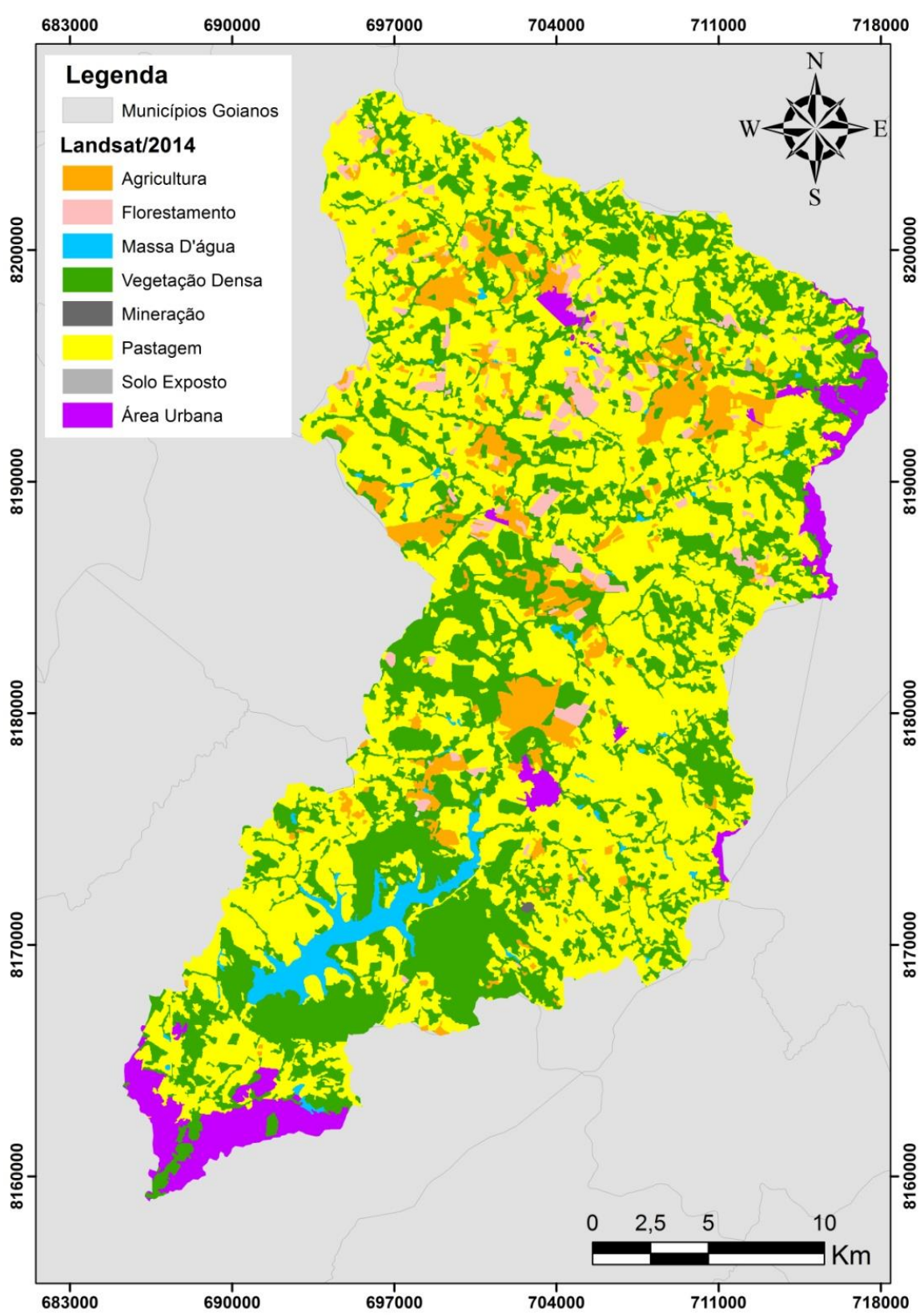

Figura 6 - Mapeamento de uso e cobertura da terra Landsat/2014. Fonte: Autores. 


\section{INFLUÊNCIA DOS DADOS E MÉTODOS NO MAPEAMENTO DO USO E DA COBERTURA DA TERRA}

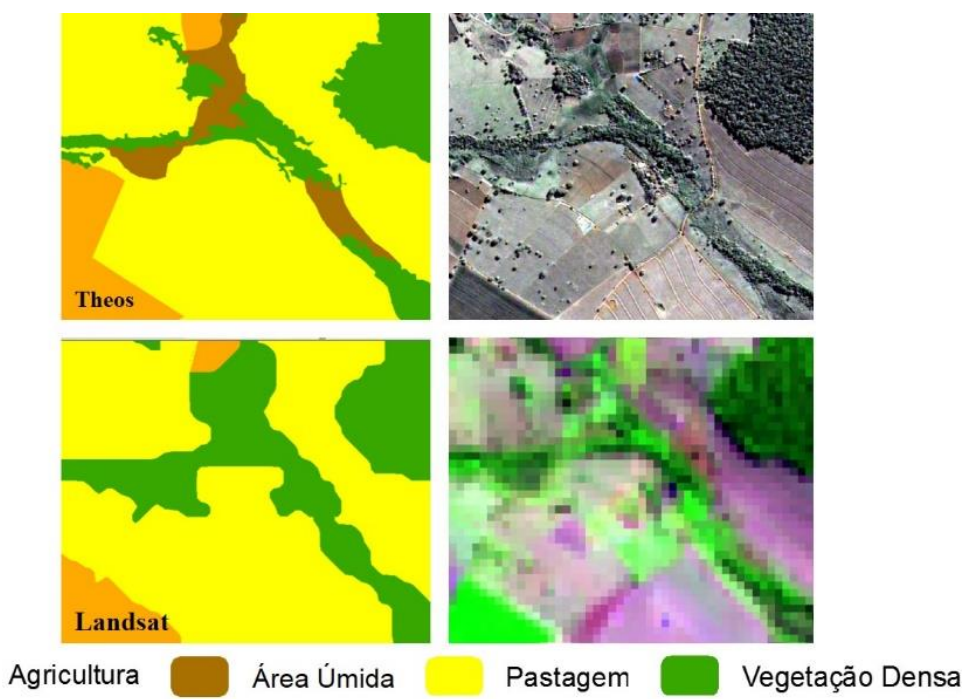

Figura 7 - Comparação de vetorização entre as classificações obtidas pelas imagens orbitais Theos e Landsat-8 OLI/2014. Fonte: Autores.

Ao realizar a quantificação entre as classes dos dois mapas constata-se que o procedimento de classificação da imagem Landsat-8 OLI gerou resultados diferentes do mapeamento utilizado como referência, Theos/Atualizado-2014 (Tabela 2). Nessa comparação, as classes que obtiveram maiores discrepâncias no valor de suas áreas foram as de pastagem e vegetação densa. A classe de pastagem foi subestimada em $50,4 \mathrm{~km}^{2}$ e, vegetação densa, superestimada em $58,7 \mathrm{~km}^{2}$. No restante das classes foi observada pouca variação absoluta, porém de considerável variação relativa, como por exemplo Massa d'água, Agricultura e Florestamento que foi superestimada em 1,8 km² (cerca de $13 \%$ da área no dado de referência), $6,4 \mathrm{~km}^{2}(11,3 \%)$ e $3,8 \mathrm{~km}^{2}$ $(17,5 \%)$, respectivamente. Enquanto que área urbana foram subestimadas em $0,2 \mathrm{~km}^{2}$.

Tabela 2 - Comparação de quantificação das classes de uso e cobertura da terra entre os mapeamentos Theos/Atualizado-2014 e Landsat/2014. Fonte: Autores.

\begin{tabular}{lccccc}
\hline \multirow{2}{*}{ Classes } & \multicolumn{2}{c}{ Theos/Atualizado-2014 } & Landsat/2014 & $\begin{array}{c}\text { Superestimação (+) ou } \\
\text { Subestimação (-) }\end{array}$ \\
\cline { 2 - 6 } & $\mathrm{Km}^{2}$ & $\%$ & $\mathrm{Km}^{2}$ & $\%$ & $\mathrm{Km}^{\mathbf{2}}$ \\
\hline Pastagem & 444,2 & 58,3 & 393,8 & 51,8 & $-50,4$ \\
Veg. Densa & $189,3^{*}$ & 25 & 247,9 & 32,6 & 58,7 \\
Agricultura & 56,2 & 7,4 & 49,9 & 6,6 & $-6,3$ \\
Área Urbana & 34,6 & 4,5 & 34,4 & 4,5 & $-0,2$ \\
Florestamento & 21,7 & 2,9 & 18,3 & 2,4 & $-3,4$ \\
Massa d'água & 14,6 & 1,9 & 16,4 & 2,2 & 1,8 \\
\hline Total & 760,7 & 100 & 760,7 & 100 & - \\
\hline
\end{tabular}

$\left(^{*}\right)$ Somatório das classes de vegetação densa e área úmida 


\section{INFLUÊNCIA DOS DADOS E MÉTODOS NO MAPEAMENTO DO USO E DA COBERTURA DA TERRA}

Tendo em vista a diferença de resolução espacial existente entre as duas imagens orbitais, esses valores indicam que, quantitativamente os valores do mapeamento Landsat/2014 não ficaram muito distantes do mapeamento Theos/Atualizado-2014. Fato que pode ser atribuído à boa pós-classificação à nível de escala, realizada manualmente com o objetivo de identificar e corrigir os erros de classificação (ou interpretação) entre classes cometidos pelo algoritmo de classificação, a fim de deixar o mais próximo possível do mapeamento de referência Theos/Atualizado-2014.

No entanto, no mapeamento Landsat/2014, a vetorização dos polígonos não foi realizada com a mesma acurácia do mapeamento Theos/Atualizado-2014. Muitos polígonos foram vetorizados além das áreas em que realmente abrangem. Isso justifica que, a superestimação de $58,7 \mathrm{~km}^{2}$ da classe de vegetação densa pode ser devido à sua apoderação sobre as demais classes, principalmente a de pastagem (Figura 8).
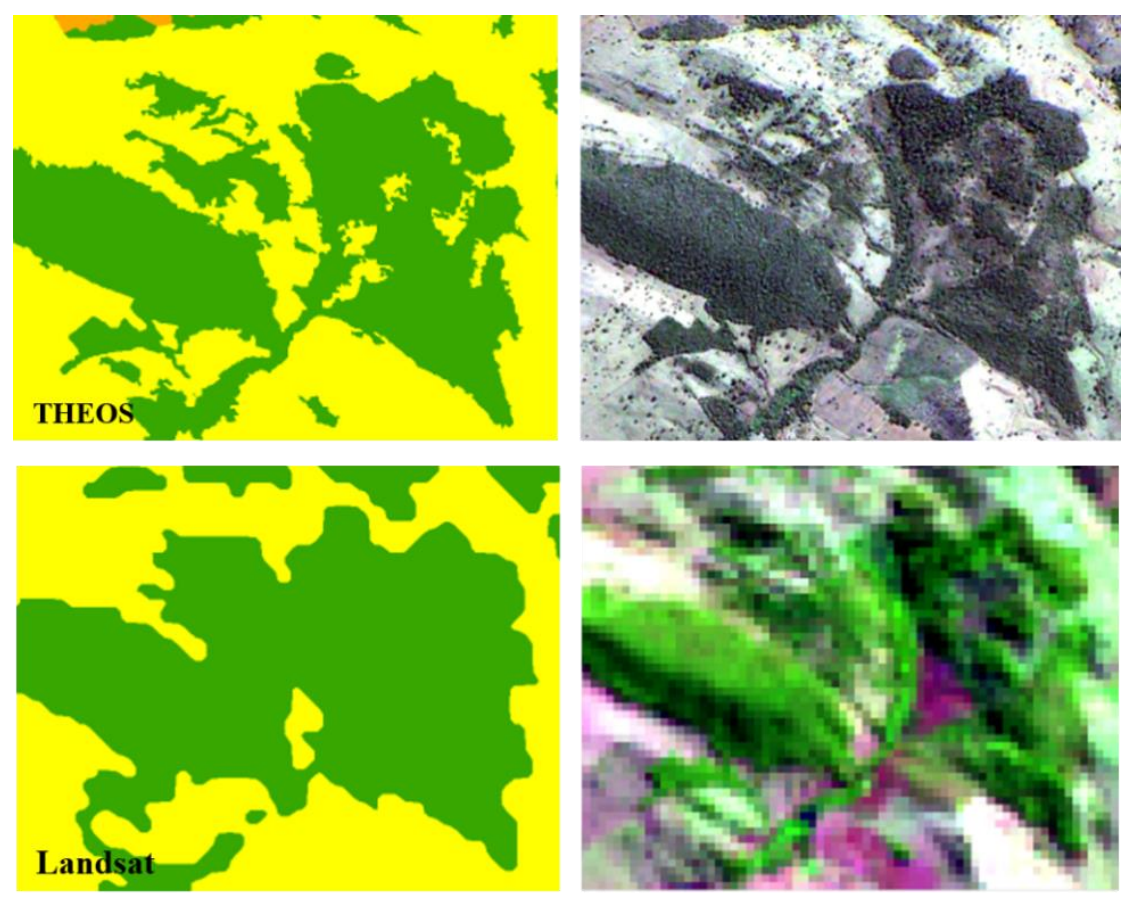

Pastagem

Vegetação Densa

Figura 8 - Diferença de vetorização da classe de vegetação densa entre o mapeamento Theos/Atualizado-2014 e Landsat-2014. Fonte: Autores.

A causa desse efeito pode ser explicada pelos valores dos limiares de similaridade e de área e, do método de segmentação adotados no procedimento de classificação da imagem Landsat-8 OLI. Analisando esses resultados, foi percebido que os valores dos limiares utilizados para a segmentação dessa imagem, para esta data, foram altos. Ao adotar o valor de 30 para o limiar de similaridade, o algoritmo de segmentação criou polígonos menos fragmentados. Enquanto que, o valor de 35 para o limiar de área, ocasionou o agrupamento de classes heterogêneas.

Caso esses limiares fossem menores, a segmentação fragmentaria os polígonos de tal forma que expressasse a realidade terrestre de maneira mais adequada, distinguindo áreas mais homogêneas. Isso significa que, a simples alteração desses limiares proporcionaria então, em outro resultado, com classes apresentando feições e dimensões bem diferentes daquelas do mapeamento Landsat/2014. 


\section{INFLUÊNCIA DOS DADOS E MÉTODOS NO MAPEAMENTO DO USO E DA COBERTURA DA TERRA}

$\mathrm{Na}$ literatura são encontrados alguns trabalhos de uso e cobertura da terra na BHRJL, sendo observadas expressivas diferenças nas quantificações das classes consideradas. Diante disso, na Tabela 3 podem ser observadas algumas comparações desses mapeamentos com os realizados nesse trabalho. Nota-se que, além dos dados utilizados, o conhecimento sobre os algoritmos de classificação e pós-classificação são fatores determinantes na elaboração desses mapeamentos. A verificação da acuracidade dos resultados também deve ser fato primordial na análise e, os resultados devem estar atrelados a uma escala de trabalho possível, e não serem colocados como fato. Apesar dos métodos e dados utilizados nos diferentes trabalhos serem adequadamente descritos, o alcance da veracidade do resultado nem sempre é deixado claro ao leitor.

Ao analisar a classe de agricultura, por exemplo, quantificada em $7,4 \%$ no mapeamento referência Theos/Atualizado-2014, observa-se mapeamentos em que as quantificações dessa mesma classe representaram 33,6\% conforme o mapeamento de 2005 realizado por Santos et al. (2010, p.829) e $38,5 \%$, conforme o mapeamento de 2009, apresentado por Oliveira (2013, p.148), o qual foi elaborado inclusive, a partir de uma imagem orbital de resolução espacial próxima à do sensor Theos (ALOS/PRISM). Apesar da comparação entre esses mapeamentos serem em períodos diferentes, não são verificados tanto nas imagens históricas do Google Earth quanto em validações em campo a predominância da classe de agricultura na BHRJL, evidenciando que tais superestimações podem ter sido ocasionadas devido aos algoritmos classificadores, características dos dados e aos processos de classificação e pós-classificação. Superestimações semelhantes nessa área ocorreram no mapeamento de uso e cobertura da terra PROBIO/2002 (oficial do Ministério de Meio Ambiente - MMA), o qual determinou até $63,6 \%$ para a classe de agricultura (RABELO et al, 2009, p.177). Ressalta-se que, o PROBIO é utilizado como base de dados na elaboração de políticas públicas de planejamento no Brasil, como por exemplo o Zoneamento Ecológico da Cana-deAçúcar (ZAE Cana) que determina áreas para a expansão sustentável do plantio da cana-deaçúcar.

Tabela 3 - Comparação de quantificações de uso e cobertura da terra da BHRJL entre diferentes fontes em relação aos mapeamentos Theos/Atualizado-2014 e Landsat/2014. Fonte: Autores.

\begin{tabular}{|c|c|c|c|c|c|}
\hline \multirow[b]{2}{*}{ Classes } & \multicolumn{5}{|c|}{ Quantificação das classes de uso e cobertura da terra (em \%) } \\
\hline & $\begin{array}{c}\text { Theos/ } \\
\text { Atualizado-2014 }\end{array}$ & $\begin{array}{c}\text { Landsat/ } \\
2014^{1}\end{array}$ & $\begin{array}{c}\text { ALOS/PRISM } \\
(2009)^{2}\end{array}$ & $\begin{array}{c}\text { Landsat-5 TM/ } \\
2005^{3}\end{array}$ & $\begin{array}{c}\text { PROBIO/ } \\
2002^{4}\end{array}$ \\
\hline Pastagem & 58,3 & 51,8 & 35,2 & 35,9 & 20,6 \\
\hline Veg. Densa & $25^{*}$ & 32,6 & 19,8 & 16,5 & 11,9 \\
\hline Agricultura & 7,4 & 6,6 & 38,5 & 33,6 & 63,6 \\
\hline Área urbana & 4,5 & 4,5 & 5,7 & 10,8 & 3,8 \\
\hline Florestamento & 2,9 & 2,4 & - & - & - \\
\hline Massa d'água & 1,9 & 2,2 & 0,6 & 0,8 & - \\
\hline Solo exposto & 0,06 & - & - & 2,4 & - \\
\hline
\end{tabular}

(1) Autores

(2) Oliveira (2013, p.148): classificação não supervisionada (K-Means) da imagem orbital ALOS/PRISM (2,5 metros de resolução espacial);

(3) Santos et al. (2010, p.829): classificação supervisionada (máxima verossimilhança) da imagem orbital Landsat-5 TM (30 metros de resolução espacial);

(4) Sano et al. (2010, p.115): classificação supervisionada (Bhattacharya) da imagem orbital Landsat-5 TM (30 metros de resolução espacial);

(-) Classe não considerada na classificação;

(*) Somatório das classes Vegetação Densa e Área Úmida. 


\section{INFLUÊNCIA DOS DADOS E MÉTODOS NO MAPEAMENTO DO USO E DA COBERTURA DA TERRA}

Em vista disso, percebe-se que, além da escolha da base de dados para a elaboração de mapeamentos de uso e cobertura da terra, a necessidade de aprimorar conhecimentos sobre os métodos e procedimentos de classificação de imagem também é essencial. Como foi observado, esse aspecto influencia os resultados, ocasionando na alteração das quantificações das classes dos mapeamentos.

Ao utilizar um único conjunto de imagens para classificação, o fato de apenas alterar os valores dos parâmetros de entrada dos classificadores, por exemplo, poderá resultar em vários mapeamentos diferentes. Entretanto, o que determinará o grau de qualidade e confiabilidade desses produtos será o conhecimento do analista sobre todo o conjunto que envolve a classificação de imagens, como: a seleção das imagens adequadas ao método de classificação a ser utilizado e ao objetivo de estudo, as técnicas de interpretação e/ou inspeção visual, os métodos e parâmetros dos classificadores de imagem e, os procedimentos pós-classificatórios.

Dentre os problemas relacionados aos mapeamentos realizados, ressalta-se a possível prejudicialidade de políticas públicas de planejamento territorial ao apontar informações associadas a níveis de esmero ou de confiabilidade, haja vista que há possibilidade de atuação dos gestores com informações errôneas da realidade, tomando decisões e afetado o diagnóstico ambiental das áreas, inclusive afetando a aplicação do código florestal. Neste sentido, frente à crescente disponibilidade e características, tanto de dados como dos métodos e ou algoritmos de manipulação desses dados, percebe-se a necessidade do estabelecimento de metodologias padrão, de modo que possam ser associados níveis de comparação.

\section{CONCLUSÃO}

Durante o período de 2011 a 2014 houve a mudanças de cobertura em 18,2 km² da BHRJL, relacionadas principalmente à expansão da agricultura e florestamento sobre pastagem e, a expansão da pastagem sobre vegetação densa. Estas mudanças são comuns em áreas de intensa ocupação agrícola, onde a ocupação da área ou os diferentes usos agrícolas tendem a mudar rapidamente.
O mapeamento Theos/Atualizado-2014 representou melhor o uso e cobertura da terra da BHRJL. Nesse mapeamento constata-se que a classe de pastagens é a predominante, correspondendo a $58,9 \%$. Com $22,2 \%$, a classe de vegetação densa é a segunda mais representativa. Enquanto que a classe de agricultura ocupa 7,4\%. O mapeamento Landsat/2014 superestimou a classe de vegetação densa e subestimou as classes de pastagem, agricultura e florestamento. Quando comparado com outros mapeamentos da literatura nacional, percebe-se diferenças significativas nas estimativas das áreas ocupadas com agricultura, inclusive em mapeamentos oficiais, que sempre superestimam em exagero estas áreas.

Diferentes dados associados principalmente à inadequada utilização dos procedimentos de classificação exercem influência nos resultados dos mapeamentos, superestimando ou subestimando as classes de uso e cobertura da terra. Nesse sentido, torna-se essencial que o analista em classificação de imagens possua conhecimento adequado para extrair o máximo possível das informações contidas nos dados, essencialmente naquelas de menor resolução espacial. Resultados incorretos podem subsidiar decisões incorretas e fornecer um diagnóstico impreciso da realidade, já que grande parte dos mapeamentos oficiais, tais como o do PROBIO, desenvolvidos no Brasil são utilizados como insumos para uma série de pesquisas, bem como direcionar políticas públicas de zoneamento, monitoramento e conservação da natureza.

Por fim, quanto aos métodos de classificação, observou-se a importância de realização da inspeção visual após o procedimento da classificação automatizada. Aqui cabe-se ressaltar a sinergia apresentada entre os dados Landsat $8 \mathrm{OLI}$, Theos e cenas do Google Earth, as quais permitiram uma análise em múltiplas resoluções espaciais, facilitando a identificação e as correções vetoriais para adequar o mapa de uso e cobertura da terra.

\section{REFERÊNCIAS}

BIOMA BRASIL - Sociedade Brasileira de Preservação e Promoção da Vida. Relatório Final do Diagnóstico Socioambiental da Bacia do Ribeirão João Leite. Goiânia, 2013, 71p. 


\section{INFLUÊNCIA DOS DADOS E MÉTODOS NO MAPEAMENTO DO USO E DA COBERTURA DA TERRA}

CAMARA, G.; SOUZA, R.C.M.; FREITAS, U.M.; GARRIDO, J.C.P. "SPRING: Integrating Remote Sensing and GIS with Object-Oriented Data Modelling". Computers and Graphics, v. 15, n. 6, p.13-22, 1996.

CEASA-GO - Central de Abastecimento do Estado de Goiás. Análise Conjuntural 2010 no 35. Divisão Técnica e Econômica, Goiânia, 2011, 237p.

OLIVEIRA, W. N. Avaliação da qualidade ambiental da paisagem da bacia hidrográfica e do reservatório do ribeirão João Leite. 2013. Dissertação (Mestrado em Engenharia do Meio Ambiente) - Escola de Engenharia Civil, Universidade Federal de Goiás, Goiânia.

RABELO, C. G.; FERREIRA, M. E.; ARAÚJO, J. V. G. de; STONE, L. F.; SILVA, S. C. da; GOMES, M. P. Influência do uso do solo na qualidade da água no bioma Cerrado: um estudo comparativo entre bacias hidrográficas no Estado de Goiás, Brasil. Revista Ambiente \& Água, Taubaté, v.4, n. 2, p. 172-187, 2009.

SANO, E. E., ROSA, R., BRITO, J. L. S.; FERREIRA, L. $G$. Land cover mapping of the tropical savanna region in Brazil. Environmental Monitoring Assessment, Orono, v. 166, n. 1-4, p. 113-124, 2010.

SANTOS, E. H. M.; GRIEBELER, N. P.; OLIVEIRA, L. F. C. Relação entre uso do solo e comportamento hidrológico na Bacia Hidrográfica do Ribeirão João Leite. Engenharia Brasileira de Engenharia
Agrícola e Ambiental, Campina Grande, v. 14, n.8, p. 826-834, 2010.

SHERMAN G. E.; SUTTON T.; BLAZEK R.; HOLL S.; DASSAU O.; MORELY B.; MITCHELL T.; LUTHMAN L. 2014. QGIS Geographic Information System. Open Source Geospatial Foundation Project. Disponível em: <http://www.qgis.org/>.

SILVA, E. B.; FERREIRA, L. G.; ANJOS, A. F.; MIZIARA, F. A expansão da fronteira agrícola e a mudança de uso e cobertura da terra no centrosul de Goiás, entre 1975 e 2010. Ateliê Geográfico, Goiânia, v. 7, n.2, p. 116-138, 2013.

SOUSA, S. B. Impactos da implantação da barragem no ribeirão João Leite sobre a oferta de hortifruti na Grande Goiânia. Boletim Goiano de Geografia, Goiânia, v. 33, n. 2, p. 155-176, 2013.

VASCONCELOS, C. H.; NOVO, E. M. L. M. Mapeamento do uso e cobertura da terra a partir da segmentação e classificação de imagens fração solo, sombra e vegetação derivadas do modelo linear de mistura aplicado a dados do sensor TM/Landsat 5, na região do reservatório de Tucuruí PA. Acta Amazonica (Impresso), Manaus, v. 34, n.1, p. 487-493, 2004.

XAVIER, F. V.; CUNHA, K. L.; SILVEIRA, A.; SALOMÃO, F. X. T. Análise da suscetibilidade à erosão laminar na Bacia do Rio Manso, Chapada dos Guimarães, MT, utilizando sistemas de informações geográficas. Revista Brasileira de Geomorfologia, São Paulo, v. 11, n. 2, p.51-60, 2010. 